\title{
Adesão ao Tratamento, Resiliência e Percepção de Doença em Pessoas com HIV $^{*, * *}$
}

\author{
Eliane Maria Fleury Seidl ${ }^{1, * * *}$ (D) \& Eduardo Remor $^{2}$ (D) \\ ${ }^{1}$ Universidade de Brasília, Brasília, DF, Brasil \\ ${ }^{2}$ Universidade Federal do Rio Grande do Sul, Porto Alegre, RS, Brasil
}

\begin{abstract}
RESUMO - O objetivo deste estudo foi investigar variáveis preditoras da adesão ao tratamento antirretroviral entre aspectos sociodemográficos, clínicos e psicológicos (resiliência e percepção de doença) em pessoas com o vírus da imunodeficiência humana (HIV). Participaram 155 pacientes, sendo 72,9\% homens. Roteiros de entrevista sobre aspectos sociodemográficos e clínicos e instrumentos validados para a população brasileira foram aplicados. Três variáveis foram preditoras da adesão: resiliência, percepção de doença como preditor negativo, e idade, totalizando $29 \%$ de variância explicada. O estudo tem implicações para a prática de psicólogos e de equipes de saúde que atuam na área, com base na implementação de intervenções visando à adesão e ao autocuidado, bem como à adaptação e à resiliência em pessoas que vivem com HIV.
\end{abstract}

PALAVRAS-CHAVE: HIV, adesão ao tratamento, resiliência, percepção de doença

\section{Treatment Adherence, Resilience and IIIness Perception in People with HIV}

\begin{abstract}
The objective of this study was to investigate predictive variables of adherence to antiretroviral treatment among sociodemographic, clinical and psychological aspects (resilience and perception of disease) in people living with the human immunodeficiency virus (HIV). Participants were 155 patients, $72.9 \%$ men. Interview scripts about sociodemographic and clinical aspects and validated instruments for the Brazilian population were applied. Three variables were predictors of adherence: resilience, perceived illness as a negative predictor, and age, with $29 \%$ explained variance. The study has implications for the practice of psychologists and health teams working in the field, based on the implementation of adherence and self-care interventions, as well as adaptation and resilience in people living with HIV.
\end{abstract}

KEYWORDS: HIV, treatment adherence, resilience, illness perception

O Brasil, desde o início da epidemia da Síndrome da Imunodeficiência Adquirida (Aids), em 1980, até junho de 2018, totalizou 982.129 casos da doença. Nos últimos cinco anos, o país tem registrado, anualmente, uma média de 40 mil casos novos (Brasil, 2018b). Progressos relevantes têm sido observados no tratamento da Aids: de doença com níveis altos de morbimortalidade nas primeiras duas décadas, atualmente é caracterizada como uma condição crônica, com tratamento e controle. O protocolo denominado Tratamento como Prevenção (TasP), que norteia as ações assistenciais no caso de infecção pelo Vírus da Imunodeficiência Humana
(HIV), recomenda o início do tratamento antirretroviral tão logo o diagnóstico esteja confirmado, independentemente da contagem de linfócitos T CD4+e da carga viral plasmática (Brasil, 2018a). A comunidade científica reconhece que o TasP é uma das medidas mais relevantes para o controle da transmissão do HIV, pois evidências científicas apontam que pessoas soropositivas que apresentam supressão viral persistente e a longo prazo (carga viral indetectável) não transmitem o HIV nas relações sexuais (Hull et al., 2014).

Outro conceito importante emerge no âmbito do monitoramento clínico das pessoas vivendo com HIV

\footnotetext{
* Pesquisa realizada em Estágio Pós-doutoral da primeira autora, com orientação do segundo autor.

** Apoio: CNPq mediante Bolsa de Produtividade em Pesquisa aos autores E. M. F. S (310704/2015-4) e E. R (302850/2017-1).

***E-mail: seidl@unb.br

- Submetido: 09/10/2019; Revisado: 04/02/2020; Aceito: 22/03/2020.
} 
(PVHIV): a cascata de cuidado contínuo que parte de indicadores (número estimado de casos), passando pelo número de pessoas diagnosticadas, seguido daquelas que estão em acompanhamento, até o número de pessoas em terapia antirretroviral (TARV) e as que alcançaram a supressão viral. Essa política, nomeada de "testou, tratou", tem implicações para as equipes de saúde, já que o número de pessoas em tratamento será maior, e muitas delas iniciarão a TARV em condição assintomática, o que traz desafios para a adesão (Nosyk et al., 2014).

No presente estudo, adesão é entendida como um "processo colaborativo que facilita a aceitação e a integração de determinado regime terapêutico no cotidiano das pessoas em tratamento, pressupondo sua participação nas decisões sobre o mesmo" (Brasil, 2008, p. 14). Trata-se de um fenômeno complexo que se constrói na experiência e vivência ao longo da enfermidade, sofrendo influência de fatores físicos, psicológicos, culturais, socioeconômicos, da doença, do tratamento e da relação profissional-usuário.

Diferentemente de outras enfermidades crônicas, as exigências dos níveis de adesão para a eficácia da TARV são rigorosas, o que representa alto custo comportamental. Não obstante protocolos mais recentes com antirretrovirais (ARVs) de última geração apontarem que a eficácia do tratamento pode ser alcançada com níveis mais baixos de adesão (iguais ou superiores a $80 \%$ das doses prescritas), a literatura ainda tem valorizado percentuais da ordem de 95\% (Brasil, 2018a).

Os desafios para mensurar a conduta de adesão são relevantes. Com o intuito de medir os níveis de adesão em PVHIV por meio de um instrumento padronizado que avalia esse construto em uma concepção multidimensional, Remor (2002) desenvolveu o Cuestionario para la Evaluación de la Adhesión al Tratamiento Antirretroviral (CEAT-VIH, sigla no original). Após aprimoramentos, a versão atual permite obter um índice de adesão global que inclui os domínios: observância do tratamento, comportamentos antecedentes de não adesão, relação médico-paciente, crenças pessoais e expectativas sobre o tratamento, e satisfação com o tratamento (Remor, 2013a; Silva et al., 2019).

Em estudo de revisão de literatura, Remor (2013b) compilou as propriedades psicométricas do CEAT-VIH mediante a análise de 20 pesquisas que usaram esse instrumento, publicadas entre 2002 e 2012, realizadas no Brasil, Portugal, Porto Rico, Colômbia, Chile, México, Peru, Panamá, Espanha e Romênia. Os resultados apontaram bons indicadores de confiabilidade na maioria dos estudos e evidências de validade relacionadas a critérios externos, responsividade, sensibilidade e especificidade, e a padrões de convergência e divergência com outras medidas estandardizadas (Remor, 2013b). Recentemente, evidências de validade analisadas em uma amostra internacional de 1470 pessoas com HIV, de 30 países, confirmaram a qualidade psicométrica do instrumento em sua versão online e multidimensional - por exemplo: dimensionalidade e estrutura, invariância fatorial para idioma e país, validade relacionada a critérios clínicos relevantes e fidedignidade (Silva et al., 2019). Uma revisão sistemática e metanalítica apontou o instrumento como o questionário específico sobre adesão mais utilizado na América Latina (Costa et al., 2018). Estudos brasileiros que utilizaram o CEAT-VIH observaram desde percentual elevado de adesão estrita e adequada, identificada em $75 \%$ dos participantes (Foresto et al., 2017), até percentual muito alto de adesão insuficiente, como 58\% (Silva et al., 2017).

Estudiosos têm explorado ainda os efeitos de variáveis sociodemográficas sobre a conduta de adesão no contexto do HIV/Aids. Os resultados são controversos, sendo possível afirmar que a variável escolaridade parece acumular mais evidências referentes à associação com níveis de adesão. Pesquisa com 80 PVHIVs verificou que as que tinham mais de oito anos de estudo relataram níveis mais altos de adesão, em comparação com as que tinham baixa escolaridade, diferença estatisticamente significativa (Foresto et al., 2017).

Em revisão de literatura, com base em 11 artigos que avaliaram a adesão ao tratamento antirretroviral em amostras brasileiras, observou-se que os níveis de não adesão variaram de $18 \%$ a $74,3 \%$. Dados sobre a retirada de medicamentos nas farmácias de dispensação e a aplicação de instrumentos validados para mensurar adesão foram os métodos mais utilizados (Garbin et al., 2017). Não obstante a variedade de procedimentos e critérios para mensurar os níveis de adesão, a conclusão foi que, de modo geral, os níveis são baixos e merecem atenção de estudiosos da área.

Em um estudo de revisão sistemática e metanálise, fruto de pesquisas feitas em 25 países da América Latina e do Caribe, foram identificados fatores associados à adesão ao tratamento (Costa et al., 2018). Os resultados indicaram que, no geral, 70\% das PVHIVs tinham níveis bons de adesão à TARV. Barreiras à adesão relatadas foram: abuso de álcool e outras drogas, depressão, desemprego ou emprego irregular e quantidade de comprimidos do esquema terapêutico. Fatores associados a bons níveis de adesão foram: presença de apoio social, boa relação médico-paciente, satisfação com o serviço de saúde. Os resultados revelaram ainda que os níveis de adesão foram maiores quanto menor era o tempo de recordação usado para mensurar a perda de doses, aspecto relevante quando se considera que medidas de autorrelato são as mais frequentes em estudos dessa natureza.

Considerando a multideterminação do conceito de adesão ao tratamento, variáveis psicológicas e psicossociais têm sido estudadas. Duas delas foram destacadas no presente estudo: resiliência e percepção de doença. No processo de saúde e adoecimento, resiliência refere-se à capacidade de uma pessoa em lidar com adversidades e estressores associados à doença, aceitando eventuais limitações decorrentes do quadro clínico, readaptando-se e vivendo de forma positiva (Araújo et al., 2017). Assim, resiliência tem sido associada a processos de promoção e manutenção da saúde mental, já que pode reduzir a intensidade dos efeitos 
do estresse e diminuir emoções negativas, como ansiedade ou depressão.

Ainda se observam controvérsias a respeito dos indicadores que contribuem para o desenvolvimento da resiliência. Stewart e Yuen (2011) realizaram uma revisão sistemática da literatura, com base em 52 artigos que pesquisaram pessoas com câncer, infecção pelo HIV, diabetes, doença cardiovascular, artrite e outras condições clínicas. A quase totalidade foi publicada a partir do ano 2000, indicando o caráter recente da produção científica sobre o tema. Os autores identificaram que variáveis psicológicas como autoeficácia, apoio social, autoestima, locus de controle interno, otimismo e aceitação da doença estiveram associadas com resiliência. Observaram também aspectos diretamente relevantes à doença física - autocuidado, adesão ao tratamento, qualidade de vida relacionada à saúde e percepção de doença - e ao processo de resiliência.

Rooke (2015), tendo em vista a crescente publicação de estudos sobre resiliência no Brasil, analisou a produção científica nacional nas bases Lilacs e SciELO, de 1970 a 2014. A autora ressaltou que as pesquisas acerca deste tema "salientam os processos de adaptação positiva como respostas no enfrentamento de adversidades significativas" (p. 3). Dos 89 trabalhos selecionados, a autora dividiu as publicações em três categorias: resiliência e adversidades, discussão do conceito resiliência e resiliência e promoção de saúde. Essa terceira categoria agregou trabalhos que relacionavam o desenvolvimento da resiliência a estratégias para redução de situações de vulnerabilidade e melhora da qualidade de vida, aspecto de grande interesse no campo da psicologia da saúde. Em outro estudo de revisão de literatura, Cal et al. (2015) selecionaram 12 artigos publicados entre 1993 e 2013 sobre resiliência e doenças crônicas. Os resultados mostraram que escores mais elevados em resiliência estiveram associados a menor depressão, ansiedade e incapacitação, melhor qualidade de vida e maior frequência de comportamentos de promoção da saúde e adesão a tratamentos.

Nas duas últimas décadas, nota-se um aumento de estudos sobre percepção de doença no campo das doenças crônicas, o que parece decorrer da maior divulgação do Modelo de Autorregulação de Leventhal, também conhecido como modelo de representação da doença ou de percepção de doença (Broadbent et al., 2006). Centrado nas crenças da pessoa sobre saúde e doença, e nas respostas aos episódios e ameaças de adoecimento, o modelo preconiza que o paciente é um agente ativo na resolução de seus problemas, reagindo de forma dinâmica à condição de enfermidade com base em sua interpretação e avaliação.

Nessa perspectiva, para Leventhal et al. (2003), face ao diagnóstico de uma enfermidade, as pessoas comumente revelam um padrão de crenças sobre essa condição que, por sua vez, é determinante dos comportamentos que serão emitidos para o gerenciamento da doença. Essas percepções ou representações influenciam diretamente as respostas emocionais do indivíduo à enfermidade, bem como a adoção de estratégias de enfrentamento para lidar com a condição (Petrie \& Weinman, 2006). Por essas razões, estudiosos têm destacado a relevância desse conceito para a prática de profissionais de saúde, a partir de resultados de pesquisas com pessoas acometidas por condições crônicas distintas - câncer, hipertensão arterial, enfermidades cardíacas e infecção pelo HIV -, que observaram associação entre percepção da doença com estratégias de enfrentamento (Norcini \& Steca, 2015), ansiedade e depressão (Castro et al., 2015), e comportamento de adesão ao tratamento (Chen et al., 2009).

Estudo com pessoas brasileiras soropositivas para o HIV observou correlação positiva estatisticamente significativa entre escores mais altos em percepção de doença (indicativos de percepções ameaçadoras da enfermidade) e ocorrência de ansiedade e depressão. Os resultados mostraram ainda correlação negativa significativa entre percepção de doença e autoeficácia para adesão à TARV, permitindo concluir que quanto maior a percepção negativa e de ameaça da infecção pelo HIV, menor a autoeficácia percebida para aderir aos ARVs (Nogueira \& Seidl, 2016a).

Considera-se que estudar resiliência e percepção de doença, em relação à adesão ao tratamento em PVHIV, investigando ainda associações entre essas variáveis e aspectos sociodemográficos e médico-clínicos, é de suma importância, pois visa à compreensão mais abrangente de respostas humanas às adversidades no contexto de doença crônica. Considerando a infecção pelo HIV como uma experiência estressante, que pode ter efeitos deletérios sobre o desenvolvimento humano e o bem-estar, estudos que explorem suas influências e o papel sobre a adesão poderão contribuir para a identificação de preditores que sejam viáveis quanto ao manejo em intervenções para a superação de dificuldades e a adaptação ao contexto de adoecimento, em prol de melhores condições de saúde e de qualidade de vida de PVHIV.

Algumas perguntas nortearam a elaboração dos objetivos do presente estudo: (a) Qual a distribuição dos participantes nos níveis de adesão avaliados pelo CEAT-VIH? (b) A distribuição dos participantes nos níveis de adesão será diferente segundo o gênero, escolaridade, situação conjugal e idade? (c) Quanto às variáveis clínicas, a adesão será diferente a depender do tempo de diagnóstico, do tempo de tratamento antirretroviral e da interrupção do tratamento por conta própria? (d) Qual a associação entre adesão autorrelatada e contagem de carga viral? (e) As variáveis psicológicas percepção de doença e resiliência serão preditoras da adesão ao tratamento em pessoas vivendo com HIV participantes do estudo? A partir do panorama exposto e dos questionamentos norteadores, o presente estudo teve como objetivo avaliar a adesão ao tratamento antirretroviral de pessoas vivendo com HIV e sua associação com variáveis sociodemográficas, clínicas e psicológicas (resiliência e percepção de doença). 


\section{MÉTODO}

\section{Tipo de Estudo}

O estudo teve delineamento transversal, com amostra de conveniência e uso de técnicas e métodos quantitativos de coleta e de análise de dados.

\section{Participantes}

Participaram do estudo 155 pessoas vivendo com HIV, adultas, de ambos os sexos, em acompanhamento médico e psicossocial em um hospital universitário de Brasília-DF. Os seguintes critérios de inclusão foram adotados: fazer acompanhamento médico no hospital; ter iniciado a TARV há, no mínimo, dois meses; possuir nível de escolaridade equivalente à terceira série do ensino fundamental.

Houve predomínio de homens $(n=113 ; 72,9 \%)$ e de pessoas com bons níveis de escolaridade $(69,6 \%$ tinham ensino médio completo ou mais). A média de idade foi igual a 40,62 $(D P=11,44)$, variando de 19 a 66 anos. O tempo de diagnóstico variou de menos de um ano a 28 anos $(M=$ $8,91 ; D P=7,48)$, assim como o tempo de uso da TARV ( $M$ $=8,13 ; D P=7,30)$. A interrupção do tratamento por conta própria foi relatada por 36 participantes $(23,2 \%)$. A maioria avaliou a adesão como muito boa ou boa $(92,9 \%)$, indicando uma percepção positiva da adesão por percentual elevado de participantes.

A carga viral (CV) indetectável foi identificada para $80,6 \%$ da amostra $(n=125)$. As estatísticas descritivas dessa variável mostraram que, no grupo de pessoas com $\mathrm{CV}$ indetectável, os valores da média e da mediana foram iguais a 50, com desvio-padrão igual a zero, já que apenas esse número é fornecido nos exames; no grupo de pessoas ( $n$ =27) com CV igual ou maior que 51, a média foi 19.339,59 $(D P=46.739,60 ; M d n=3.323 ;$ mínimo $=53 ;$ máximo $=$ 197.832), indicando que houve predomínio de cargas virais detectáveis relativamente baixas, tendo por base os valores mínimos e da mediana. Os níveis dos linfócitos T CD4+ foram elevados: a média foi igual a $682,4(D P=361,18)$, $89,7 \%$ dos participantes estavam com CD4 superior a 200 , sendo que $39,4 \%$ tinham níveis superiores a 700 células. A caracterização sociodemográfica e médico-clínica dos participantes está apresentada na Tabela 1 .

\section{Instrumentos}

Foi elaborado um roteiro de entrevista, abordando os seguintes aspectos: (a) aspectos sociodemográficos: sexo, idade, escolaridade, situação conjugal, situação empregatícia e renda familiar; e (b) aspectos médico-clínicos: tempo de diagnóstico, tempo de tratamento de terapia antirretroviral, interrupção do tratamento com ARV por conta própria, autoavaliação da adesão ao tratamento. Indicadores laboratoriais, como contagem dos linfócitos T CD4+ e da carga viral plasmática (últimos exames), foram obtidos de fonte secundária, no caso, o prontuário.

O Questionário para Avaliação da Adesão ao Tratamento Antirretroviral (CEAT-VIH, versão on-line) foi adaptado por Remor et al. (2007) e Silva et al. (2019), a partir da versão original em língua espanhola (Remor, 2002), e apresenta evidências de validade para a língua portuguesa (falada no Brasil). O instrumento, em sua versão atual com 17 itens (Remor, 2013a), avalia a adesão ao tratamento antirretroviral mediante autorrelato, em uma concepção multidimensional, incluindo os domínios: observância do tratamento, comportamentos antecedentes de não adesão, relação médico-paciente, crenças pessoais e expectativas sobre o tratamento e satisfação com o tratamento. As alternativas de resposta são dadas em escala Likert de 5 pontos. Permite o cálculo de um escore global (e por dimensão), bruto, de adesão, obtido pela soma das respostas, variando de 17 a 85 pontos, sendo que escores mais altos representam níveis melhores de adesão. Optou-se pela avaliação do nível global de adesão. Outra possibilidade de análise refere-se à distribuição da amostra conforme os percentis, procedimento que também foi adotado, transformando a variável contínua em categórica, em dois níveis: adesão estrita e não estrita/ insuficiente. Foi aplicada a versão on-line, por sua fácil utilização e correção, que favorece o retorno imediato ao participante sobre seu nível de adesão e suas dimensões, mediante gráficos que são gerados a partir das respostas dadas. O instrumento apresenta propriedades psicométricas robustas (Silva et al., 2019). A autorização formal para uso do CEAT-VIH no presente estudo foi dada pelo autor. A consistência interna (alfa de Cronbach) obtida na amostra desse estudo foi igual a 0,68 para o conjunto de 17 itens.

O Questionário de Percepção de Doenças Versão Breve é adaptado e validado no Brasil (Nogueira \& Seidl, 2016b), desenvolvido a partir de instrumento original em língua inglesa (Broadbent et al., 2006), composto de sete itens que são respondidos utilizando uma escala de 0 a 10 . Ao final da escala, há duas questões abertas - dimensão temporal e causalidade da condição - não analisadas no presente estudo. A B-IPQ na versão brasileira possui dois fatores: representação emocional (quatro itens) e representação cognitiva (três itens), podendo ser usada na versão unifatorial, que foi adotada no presente estudo. Um escore alto reflete maior percepção de ameaça da doença (amplitude de 0-70). Quanto mais próximo de 70 for o escore, maior a percepção de ameaça imposta pela enfermidade. Sugere-se considerar que a pessoa tem uma percepção de relevante ameaça quando o escore for superior a 33: o escore médio dos participantes da pesquisa de validação foi utilizado como ponto de corte (Nogueira \& Seidl, 2016b). A consistência interna (alfa de Cronbach) obtida na amostra do presente estudo foi igual a 0,73 . 
Tabela 1

Caracterização Sociodemográfica e Médico-Clínica dos Participantes $(N=155)$

\begin{tabular}{|c|c|c|}
\hline \multicolumn{2}{|c|}{ Variáveis sociodemográficas } & \multirow{2}{*}{$\begin{array}{c}\boldsymbol{F}(\mathbf{\%}) \\
113(72,9) \\
42(27,1)\end{array}$} \\
\hline Gênero & $\begin{array}{l}\text { Masculino } \\
\text { Feminino }\end{array}$ & \\
\hline Escolaridade & $\begin{array}{l}\text { Ensino fundamental incompleto } \\
\text { Ensino fundamental completo } \\
\text { Ensino médio incompleto } \\
\text { Ensino médio completo } \\
\text { Ensino superior incompleto } \\
\text { Ensino superior completo }\end{array}$ & $\begin{array}{l}25(16,1) \\
12(7,7) \\
10(6,5) \\
51(32,9) \\
25(16,1) \\
32(20,6)\end{array}$ \\
\hline Situação conjugal & $\begin{array}{l}\text { Vive com esposo(a) ou companheiro(a) } \\
\text { Solteiro(a) } \\
\text { Separado(a), viúvo(a) ou divorciado(a) }\end{array}$ & $\begin{array}{l}45(29,0) \\
52(33,5) \\
58(37,4)\end{array}$ \\
\hline Situação empregatícia & $\begin{array}{l}\text { Emprego fixo (com direitos trabalhistas) } \\
\text { Emprego fixo (sem direitos trabalhistas) } \\
\text { Trabalho autônomo (regular ou eventual) } \\
\text { Aposentado } \\
\text { Benefício de prestação continuada } \\
\text { Desempregado/não trabalhando } \\
\text { Outra }\end{array}$ & $\begin{array}{c}50(32,3) \\
03(01,9) \\
28(18,1) \\
20(12,9) \\
14(9,0) \\
29(18,7) \\
11(7,1)\end{array}$ \\
\hline $\begin{array}{l}\text { Renda familiar } \\
\text { (em salários mínimos) }\end{array}$ & $\begin{array}{l}0 \text { a } 1 \mathrm{SM} \\
2 \text { a } 3 \mathrm{SM} \\
4 \text { a } 5 \mathrm{SM} \\
6 \text { a } 10 \mathrm{SM} \\
\text { Mais de } 11 \mathrm{SM}\end{array}$ & $\begin{array}{c}32(20,6) \\
77(49,7) \\
15(9,7) \\
23(14,8) \\
8(5,2)\end{array}$ \\
\hline & dico-clínicas & $F(\%)$ \\
\hline $\begin{array}{l}\text { Tempo de diagnóstico (em anos) } \\
M=8,91 D P=7,48 \\
\text { Amplitude: }<1 \text { ano a } 28 \text { anos }\end{array}$ & $\begin{array}{l}<1 \text { a } 3 \text { anos } \\
4 \text { a } 9 \text { anos } \\
>10 \text { anos }\end{array}$ & $\begin{array}{l}55(35,5) \\
32(20,6) \\
68(43,9)\end{array}$ \\
\hline $\begin{array}{l}\text { Tempo de TARV (em anos) } \\
M=8,13 D P=7,30 \\
\text { Amplitude: }<1 \text { ano a } 28 \text { anos }\end{array}$ & $\begin{array}{l}<1 \text { a } 3 \text { anos } \\
4 \text { a } 9 \text { anos } \\
>10 \text { anos }\end{array}$ & $\begin{array}{l}62(40,0) \\
33(21,3) \\
60(38,7)\end{array}$ \\
\hline $\begin{array}{l}\text { História de interrupção do } \\
\text { tratamento por conta própria }\end{array}$ & $\begin{array}{l}\text { Não } \\
\text { Sim }\end{array}$ & $\begin{array}{l}119(76,8) \\
36(23,2)\end{array}$ \\
\hline Autoavaliação da adesão & $\begin{array}{l}\text { Muito boa } \\
\text { Boa } \\
\text { Regular } \\
\text { Precária/Ruim }\end{array}$ & $\begin{array}{l}89(57,4) \\
55(35,5) \\
9(5,8) \\
2(1,2)\end{array}$ \\
\hline $\begin{array}{l}\text { Linfócitos T CD4 }{ }^{1} \\
M=682,04 D P=361,18 \\
\text { Amplitude: } 40 \text { a } 1800\end{array}$ & $\begin{array}{l}\leq 200 \\
201 \text { a } 700 \\
\geq 701\end{array}$ & $\begin{array}{l}16(10,3) \\
78(50,3) \\
61(39,4)\end{array}$ \\
\hline $\begin{array}{l}\text { Carga Viral }^{1} \\
M=3476,44 D P=20.757,38 \\
\text { Amplitude: } \leq 50 \text { a } 197.832\end{array}$ & $\begin{array}{l}\leq 50 \text { cópias (indetectável) } \\
51 \text { a } 5.000 \text { cópias } \\
\geq 5.001 \text { cópias }\end{array}$ & $\begin{array}{c}125(80,6) \\
18(11,6) \\
12(7,7)\end{array}$ \\
\hline
\end{tabular}

Nota. ${ }^{1}$ Três casos com dados perdidos, $n=152$

A Escala de Resiliência de Connor-Davidson (CD-RISC 25) para brasileiros foi elaborada em sua versão original em língua inglesa por Connor e Davidson (2003), traduzida e validada para o português do Brasil por Solano et al. (2010). O instrumento autoaplicável possui 25 itens que avaliam a percepção dos indivíduos acerca da capacidade de adaptação à mudança, de superação de obstáculos, bem como de se recuperarem após doenças, lesões ou outras dificuldades. $\mathrm{O}$ instrumento possui quatro fatores: tenacidade, adaptabilidade-tolerância, amparo e intuição.
Os participantes registraram suas respostas em uma escala Likert de 5 pontos: 0 (nem um pouco verdadeiro) a 4 (quase sempre verdadeiro). Os escores, computados mediante a soma da pontuação de cada item, variam de 0 a 100 : quanto maior o escore, maiores os níveis de resiliência. A solicitação para uso da CD-RISC-25 nesta pesquisa foi feita aos autores norte-americanos, que autorizaram o uso da escala. A consistência interna (alfa de Cronbach) na presente amostra foi igual a 0,88 . 


\section{Procedimento}

\section{Coleta de Dados}

Inicialmente o projeto foi submetido ao Comitê de Ética em Pesquisa do Instituto de Ciências Sociais e Humanas da Universidade de Brasília para aprovação e autorização quanto ao início da coleta de dados (Parecer $n^{\circ} 2.634 .587$ ). Foi realizada uma etapa piloto, com cinco pacientes da unidade de saúde, com níveis diversos de escolaridade, para avaliar a adequação dos procedimentos propostos e o nível de compreensão e entendimento dos instrumentos. A aplicação mostrou que a sequência dos instrumentos estava adequada, com boa compreensão pelos participantes acerca do conteúdo dos instrumentos, sendo que nenhuma alteração foi necessária.

Os participantes foram convidados a participar quando estavam no serviço para consultas, exames, em salas de espera para atendimentos da psicologia ou do serviço social ou para busca de medicamentos na farmácia. Inicialmente foi feita a entrevista para obtenção de dados sociodemográficos e médico-clínicos, seguidos do CD RISC-25, B-IPQ (ambos autoaplicados na modalidade impressa) e o CEAT-VIH (aplicado na versão on-line). A aplicação do CEAT-VIH foi assistida, e o feedback referente aos resultados, pela visualização da tela final que resume os escores do participante, foi dado após o término do preenchimento de todos os instrumentos. Esse momento educativo foi muito importante, pois visou informar sobre a conduta de adesão. Essa atividade se constituiu em uma intervenção breve, focada em adesão, permitindo ainda a oferta de atendimento específico, em outro momento a ser definido, nos casos que requeriam mais atenção, respeitando a disponibilidade e o interesse do paciente.

A coleta de dados foi efetuada pela pesquisadora e por auxiliares de pesquisa treinados. Também foram garantidas condições de conforto durante a aplicação (ventilação, ausência de ruído e iluminação), além de confidencialidade e sigilo. O tempo da resposta aos instrumentos foi de 40 minutos, em média.

\section{Análise dos Dados}

Procedeu-se à análise descritiva (frequência, medidas de dispersão e tendência central) das variáveis sociodemográficas, clínicas e psicológicas. As variáveis categóricas foram analisadas quanto à frequência e proporção. A análise exploratória de dados visou identificar a adequação das variáveis quanto aos pressupostos exigidos para análises multivariadas (normalidade, linearidade, multicolinearidade). A consistência interna das escalas CEAT-VIH, B-IPQ e CD RISC-25 foram examinadas pelo alfa de Cronbach. A investigação de validade de critério da CEAT-VIH foi efetuada mediante a associação com a variável carga viral plasmática. Análises bivariadas paramétricas ou não paramétricas foram realizadas para identificar níveis de associação ou de correlação, mediante o uso de técnicas estatísticas adequadas ao tipo de variável (contínuas ou categóricas). O nível de significância de 5\% foi adotado no estudo. Por fim, foi realizada uma análise multivariada (regressão linear múltipla) para identificação dos preditores da adesão ao tratamento antirretroviral. O pacote estatístico SPSS (Statistical Package for Social Sciences) foi utilizado na análise de dados.

\section{RESULTADOS}

Esta seção está organizada em três tópicos: adesão, resiliência e percepção de doença: análises descritivas; análises bivariadas entre as variáveis do estudo; e investigando os preditores da adesão autorrelatada.

\section{Adesão, Resiliência e Percepção de Doença: Análises Descritivas}

O escore médio global (bruto) no presente estudo foi igual a 76,15 $(D P=5,85 ; M d n=75,86$; mínimo $=55$; máximo $=85)$. Considerando que estudos prévios com o CEAT-VIH também utilizaram o percentil como parâmetro para o ponto de corte, os escores da variável adesão foram categorizados em dois níveis, utilizando o percentil 80 como ponto de corte (escore bruto 81), com base em resultados de estudos internacionais (Silva et al., 2019). Escores brutos iguais ou maiores que 81 foram obtidos por 35 participantes
$(22,6 \%)$, classificados como adesão estrita; escores iguais ou menores que 80 foram obtidos por 120 pessoas $(77,4 \%)$, representando adesão insuficiente (não estrita).

No que tange à variável resiliência, as análises descritivas mostraram que, não obstante a acentuada amplitude, os escores médios foram elevados igual a 70,40 $(D P=15,01$; $M d n=72 ;$ mínimo $=18 ;$ máximo $=100)$, revelando bons níveis médios de resiliência na amostra estudada. Quanto à percepção de doença, os resultados da estatística descritiva também revelaram que a maioria dos participantes não percebia a condição de soropositividade como ameaça relevante, já que a média foi igual a 26,23 $(M d n=28 ; D P$ $=12,66$, mínimo $=0$; máximo $=57$ ).

Considerando que a carga viral é uma medida objetiva e considerada padrão-ouro para averiguar a eficácia da TARV, uma análise de associação entre adesão autorrelatada pelos participantes e carga viral foi realizada. Entre os 35 participantes que tinham adesão estrita de acordo com 
o CEAT-VIH, $31(88,6 \%)$ tinham CV indetectável $(\leq 50$ cópias virais por $\mathrm{ml})$, e quatro $(11,4 \%)$ tinham carga viral detectável ( $\geq 51$ cópias virais por $\mathrm{ml}$ ). Quanto aos 120 que obtiveram escores compatíveis com adesão insuficiente (não estrita), 94 (78,3\%) tinham CV indetectável e $26(21,7 \%)$ tinham CV detectável $(\geq 51)$. No teste qui-quadrado esta distribuição (adesão estrita e não estrita com $\mathrm{CV}$ detectável e CV indetectável) não foi significativa $\left(\chi^{2}=1,82 ; g . l .=1\right.$; $p=0,18)$.

A associação entre adesão e resiliência mostrou que as médias dos escores foram estatisticamente diferentes para os dois grupos: o que estava com adesão estrita teve média mais alta $(M=78,57 ; D P=13,72)$ em comparação ao que estava com adesão insuficiente (não estrita) $(M=68,02 ; D P$ $=14,58)$, segundo o teste $t$ de Student $(t=3,95 ; p \leq 0,001)$. O cálculo do tamanho de efeito indicou um $d$ de Cohen de 0,75 (efeito médio). No caso de percepção de doença, as médias dos escores também alcançaram significância estatística $(t=$ $-2,40 ; p \leq 0,05)$ : adesão estrita obteve escore médio igual a $21,63(D P=13,10)$ e adesão insuficiente (não estrita) igual a $27,58(D P=12,27)$. O tamanho de efeito indicou um $d$ de Cohen de 0,47 (efeito pequeno).

\section{Análises Bivariadas com a Variável Adesão ao Tratamento}

Análises bivariadas foram realizadas com a variável critério adesão, como medida contínua, com as variáveis sociodemográficas e clínicas. No caso das variáveis antecedentes contínuas, como idade, tempo de diagnóstico, tempo de TARV, resiliência e percepção de doença, coeficientes de correlação foram identificados. Na Tabela 2 estão os valores dos coeficientes de correlação entre a variável adesão e as cinco variáveis antecedentes contínuas. Destaca-se a correlação positiva entre adesão e idade ( $r=$ $0,21 ; p \leq 0,01)$ e resiliência $(r=0,44 ; p \leq 0,001)$, além de associação negativa com percepção de doença $(r=-0,42$; $p \leq 0,001)$. Assim, melhores níveis de adesão estiveram correlacionados com idade mais elevada, escores mais altos de resiliência e mais baixos de percepção da doença, condição percebida, portanto, como menos ameaçadora. Outra correlação negativa foi entre resiliência e percepção de doença $(r=-0,34 ; p \leq 0,001)$.

A correlação forte entre tempo de diagnóstico e tempo de TARV $(r=0,95 ; p \leq 0,01)$, bem como entre estas duas variáveis e idade, era esperada e decorre das associações temporais entre estes indicadores: idade mais elevada, maior tempo de diagnóstico e, consequentemente, mais tempo de tratamento (Tabela 2).

No que se refere às variáveis categóricas com duas condições (gênero, situação empregatícia e interrupção do tratamento por conta própria), agrupadas em dois níveis (por exemplo, trabalhando versus não trabalhando), os resultados referentes ao teste $t$ de Student estão na Tabela 3. As variáveis escolaridade e situação conjugal, divididas em três condições, foram analisadas pela ANOVA pos hoc Scheffè (Tabela 3). Constatou-se que a adesão não teve escores médios diferentes no que tange à significância estatística nas seis variáveis categóricas do estudo.

\section{Investigando os Preditores da Adesão Autorrelatada}

Inicialmente foi verificada a viabilidade da análise de regressão múltipla padrão. Investigou-se a existência de casos discrepantes univariados nas variáveis resiliência, percepção de doença e adesão autorrelatada (escore global). Foram identificados dois casos, não extremos, ambos nos limites inferiores, um na variável resiliência e outro em adesão. Optou-se por não realizar qualquer procedimento de reajuste dos escores desses casos, dado o número reduzido e para respeitar o dado empírico. Com base no critério da distância Mahalanobis $\left(\chi^{2}=18,467 ; p \leq 0,001\right)$, os outliers multivariados foram pesquisados e nenhum caso discrepante foi identificado.

Tabela 2

Correlações de Pearson entre Adesão, Idade, Tempo de Diagnóstico, Tempo de TARV, Resiliência e Percepção de Doença $(N=155)$

\begin{tabular}{lccccc}
\hline \multicolumn{1}{c}{ Variáveis } & $\begin{array}{c}\text { Adesão ao } \\
\text { tratamento }\end{array}$ & Idade & $\begin{array}{c}\text { Tempo de } \\
\text { diagnóstico }\end{array}$ & Tempo de TARV & Resiliência \\
\hline Adesão ao tratamento & --- & & & \\
Idade & $0,21^{* *}$ & --- & --- & & \\
Tempo de diagnóstico & 0,14 & $0,63 * * *$ & $0,95^{* * *}$ & -- \\
Tempo de TARV & 0,14 & $0,64^{* * *}$ & $0,17^{*}$ & $0,19^{*}$ & $-0,09$ \\
Resiliência & $0,44^{* * *}$ & 0,15 & $-0,09$ & $-0,34^{* * *}$ \\
Percepção de doença & $-0,42^{* * *}$ & 0,06 & & - \\
\hline
\end{tabular}

$* p \leq 0,05 ; * * \leq 0,01 ; * * * p \leq 0,001$ 
Tabela 3

Escores Médios de Adesão ao Tratamento (Escore Bruto) Segundo Gênero, Situação Empregatícia, Interrupção do Tratamento, Escolaridade e Situação Conjugal $(N=155)$

\begin{tabular}{|c|c|c|c|c|}
\hline & Variáveis & $M$ & $D P$ & t/ANOVA (p-valor) \\
\hline \multirow{2}{*}{ Gênero } & Homens & 76,16 & 5,93 & $0,02(0,98)$ \\
\hline & Mulheres & 76,14 & 5,94 & \\
\hline \multirow{2}{*}{ Situação empregatícia } & Trabalhando & 76,48 & 5,24 & $0,72(0,47)$ \\
\hline & Não trabalhando & 75,80 & 6,48 & \\
\hline \multirow{2}{*}{ Interrupção do tratamento } & Não & 76,45 & 5,84 & $1,15(0,25)$ \\
\hline & Sim & 75,17 & 5,89 & \\
\hline \multirow{3}{*}{ Escolaridade } & Fundamental incompleto e completo & 75,65 & 5,56 & $0,43(0,65)$ \\
\hline & Médio incompleto e completo & 75,91 & 5,96 & \\
\hline & Superior incompleto e completo & 76,70 & 6,04 & \\
\hline \multirow{3}{*}{ Situação conjugal } & Solteiro(a) & 75,56 & 5,74 & $0,65(0,52)$ \\
\hline & Casado(a) ou em união consensual & 76,00 & 6,46 & \\
\hline & Separado(a), divorciado(a), viúvo(a) & 76,81 & 5,50 & \\
\hline
\end{tabular}

O pressuposto de normalidade foi investigado mediante os histogramas das variáveis métricas do estudo, dos valores de simetria e curtose, bem como por meio do teste Kolmogorov-Smirnov. O pressuposto de normalidade foi violado na variável adesão ao tratamento $(K S=1,64 ; p$ $=0,009)$, mas não em resiliência $(K S=1,00 ; p=0,26) \mathrm{e}$ percepção de doença $(K S=0,97 ; p=0,30)$. Optou-se por não proceder a qualquer transformação na variável adesão, mantendo o banco de dados original. Gráficos de dispersão entre pares de variáveis não revelaram problemas de ausência de linearidade.

Optou-se por incluir como variáveis preditoras aquelas que tiveram associação significativa $(p \leq 0,05)$ com a variável critério nas análises bivariadas, a saber: idade, resiliência e percepção de doença. Problemas de colinearidade entre as variáveis preditoras não foram identificados, tendo em vista a ausência de correlações acima de 0,40 na matriz. Outros indicadores observados foram o fator de inflação da variância (FIV) de cada variável, que foi abaixo de 5, variando de 1,45 a 1,08 ; a estatística tolerância de cada variável não foi acima de 0,20 . Para a investigação dos preditores da adesão ao tratamento, foi realizada análise de regressão múltipla padrão, considerando como variáveis antecedentes idade, percepção de doença e resiliência. Essas variáveis foram selecionadas tendo em vista os resultados de análises bivariadas preliminares, quando foram identificadas associações estatisticamente significativas.

$\mathrm{Na}$ Tabela 4 estão os resultados da análise de regressão, com os valores dos coeficientes de regressão não padronizados $(B)$, os coeficientes de regressão padronizados $(\beta)$, as correlações semiparciais ao quadrado $\left(s r^{2}\right)$, o coeficiente de determinação $\left(R^{2}\right)$ e o $R^{2}$ ajustado relativo à variável adesão ao tratamento. Os resultados indicaram que três variáveis antecedentes contribuíram de modo significativo para a predição: percepção de doença, mais forte preditor, com $9 \%$ de contribuição para a variância da adesão $\left(s r^{2}\right.$ $=0,09)$; seguida de resiliência, com $8 \%\left(s r^{2}=0,08\right)$; e da idade, com $3 \%$ de contribuição $\left(s r^{2}=0,03\right)$. Assim, as três variáveis alcançaram $20 \%$ de variabilidade única, ou seja, a soma da contribuição de cada uma delas na explicação da variância da adesão. Assim, 31\% (29\% ajustado) da variância da adesão pode ser explicada com base nos escores dessas três variáveis antecedentes (Tabela 4). Concluindo, melhores níveis de adesão resultaram de escores baixos em percepção de doença (significando menor ameaça percebida na condição de soropositividade), escores mais altos em resiliência e idade mais elevada na amostra de pessoas soropositivas que participaram do estudo. 
Tabela 4

Regressão Múltipla Padrão das Variáveis Idade, Resiliência e Percepção de Doença, em Relação à Adesão ao Tratamento $(N=155)$

\begin{tabular}{|c|c|c|c|c|c|c|c|}
\hline Variáveis & 1 & 2 & 3 & 4 & B & $\boldsymbol{\beta}$ & $s r^{2}$ \\
\hline 1. Adesão a tratamento & - & & & & - & - & - \\
\hline 2. Idade & $-0,21 * *$ & - & & & 0,14 & $0,18^{* *}$ & 0,03 \\
\hline 3. Resiliência & $0,44 * * *$ & 0,15 & - & & 0,17 & $0,31 * * *$ & 0,08 \\
\hline 4. Percepção de doença & $-0,42 * * *$ & 0,06 & $-0,34 * * *$ & - & $-0,22$ & $-0,32 * * *$ & 0,09 \\
\hline médias & 76,15 & 40,62 & 70,40 & 26,23 & & & Intercepto $=74,84$ \\
\hline \multirow[t]{3}{*}{ desvios-padrão } & 5,86 & 11,44 & 15,01 & 12,66 & & & $R^{2}=0,31$ \\
\hline & & & & & & & $R^{2}$ ajustado $=0,29$ \\
\hline & & & & & & & $R=0,55$ \\
\hline
\end{tabular}

$* p \leq 0,05 ; * * p \leq 0,01 ; * * * \leq 0,001 ;$ variabilidade única $=20 \%$

\section{DISCUSSÃO}

O objetivo deste estudo foi investigar os níveis de adesão à TARV e sua associação com variáveis sociodemográficas, clínicas e psicológicas, tema de alta relevância, tendo em vista que a adesão ao tratamento está relacionada à supressão viral no plasma sanguíneo, reduzindo a progressão para a condição de Aids e os níveis de transmissão do HIV, meta das políticas públicas brasileiras na área (Brasil, 2018a).

As características sociodemográficas na amostra de conveniência foram compatíveis com as tendências epidemiológicas atuais. Cerca de dois terços dos participantes eram homens, o que vai ao encontro do crescimento da prevalência de casos nesse segmento populacional, observando-se uma redução dos casos de Aids em mulheres e um aumento em homens (Brasil, 2018a). Outro aspecto relevante se refere ao bom nível de escolaridade dos participantes: $65 \%$ cursaram pelo menos o ensino médio completo. Apesar desses níveis de escolaridade, os valores de renda familiar foram baixos, provavelmente devido às condições precárias de emprego e renda no país.

Indicadores apontam bons níveis de adesão na amostra estudada. A grande maioria avaliou sua adesão como muito boa ou boa; $80 \%$ dos participantes estavam com carga viral indetectável, segundo dados de exames laboratoriais. Os resultados do CEAT-VIH foram coerentes com esses indicadores, quando se considerou a adesão como variável contínua, tendo em vista que a média do escore global foi elevada, assim como os valores máximos e mínimos. Os bons níveis de adesão dos participantes foram ao encontro de resultados de pesquisas que também observaram médias altas no CEAT-VIH. No entanto, o fato de o CEAT-VIH ser um instrumento que parte do conceito multidimensional de adesão e adota níveis rigorosos na avaliação dessa conduta (indo além da observância e do cumprimento) fez com que um percentual relativamente alto nessa amostra fosse classificado com adesão insuficiente (não estrita), quando usado o percentil 80 como ponto de corte. Esse método tem por base estudos do CEAT-VIH em nível internacional (Silva et al., 2019), e fez com que cerca de $75 \%$ da amostra fosse classificada com adesão insuficiente (não estrita). Formulamos a hipótese de que outros fatores podem ter afetado o escore dessa variável: (a) o tratamento antirretroviral atual é altamente eficaz, mesmo diante de eventuais omissões de doses do medicamento; (b) o instrumento considera outras dimensões do tratamento e cuidado de saúde, como, por exemplo, satisfação com o tratamento, comunicação médico-paciente, crenças e expectativas sobre o tratamento. À guisa de exemplo, um paciente pode apresentar boa observância quanto ao uso da medicação que repercuta no controle da carga viral, porém, pode perceber que há dificuldade na comunicação com seu médico, podendo refletir negativamente na satisfação com o tratamento. Isso poderia explicar por que parte dos pacientes que apresentavam supressão viral foram classificados pelo escore global do instrumento como insuficiente (não estrita).

O escore médio igual a 70,40 no CD-RISC revelou que os participantes estavam com bons níveis de resiliência, mas com variabilidade na amostra. Quanto à percepção de doença, os resultados também foram bons, já que a média foi igual a 26,23 , e quanto mais baixo o escore - em especial menor que 33, ponto de corte estabelecido no estudo de validação (Nogueira \& Seidl, 2016a) -, menos evidência de que a condição é percebida como muito ameaçadora e de forma negativa. O coeficiente de correlação negativo e significativo entre essas duas variáveis fez sentido, pois escores mais altos em resiliência estiveram associados à percepção menos negativa e ameaçadora da soropositividade, indo ao encontro da literatura (Cal et al., 2015; Nogueira \& Seidl, 2016a). Notou-se que as variáveis clínicas não tiveram efeitos sobre a adesão, assim como as sociodemográficas, exceto a idade. Quanto às variáveis psicológicas foi diferente: níveis mais altos de resiliência e percepção menos ameaçadora da doença foram preditores da adesão. No entanto, o percentual de variância explicada foi relativamente modesto, indicando a necessidade de 
investigar outros aspectos que podem afetar a adesão no contexto da soropositividade para o HIV.

Os instrumentos usados são de fácil aplicação e se mostraram acessíveis e compreensíveis para pessoas com diferentes níveis de escolaridade, além de apresentar bons indicadores de consistência interna identificados na amostra do presente estudo. Conclui-se que são ferramentas úteis e válidas para utilização em serviços de saúde que atendem a pessoas soropositivas, permitindo a avaliação de aspectos importantes como percepção da doença e resiliência, além da adesão ao tratamento. A aplicação do CEAT-VIH no formato on-line se mostrou de grande utilidade, permitindo que as pessoas tivessem um feedback imediato sobre seus níveis de adesão. A possibilidade de visualizar o gráfico que expressava as respostas dadas sobre as dimensões da adesão foi didático e muito esclarecedor, evidência disso é que a maioria dos participantes pediu que o gráfico fosse enviado para seu $e$-mail pessoal. Essa aplicação permitiu a identificação de pessoas com dificuldades de adesão ou em risco de rupturas dessa conduta, para as quais foi proposto acompanhamento específico, muitas delas tendo aceitado o atendimento focado em adesão com a psicologia.

Contudo, algumas limitações devem ser consideradas ao interpretar os resultados do presente estudo: (a) o delineamento transversal não permite inferir causalidade ou efeitos entre as variáveis; (b) a amostra foi selecionada de forma não probabilística; (c) a inclusão de pessoas acompanhadas em um único hospital dificulta a generalização dos resultados. Vale ressaltar que o serviço de saúde da coleta de dados possui equipe interdisciplinar e atendimento diferenciado, aspecto que pode ter influenciado nos bons níveis de adesão, de percepção de doença e de resiliência. Em estudos futuros, poder-se-ia propor a ampliação para outros serviços de saúde, com amostras representativas do contexto brasileiro.

Para além das limitações, os resultados permitem recomendar a implementação de intervenções baseadas em evidência, em grupo ou individual, dirigidas a pessoas com percepção negativa e ameaçadora da doença e baixos níveis de resiliência, com problemas ou não de adesão ao tratamento, dadas as associações e interações entre tais variáveis. Espera-se que a pesquisa atual contribua para alertar psicólogos e equipes de saúde que atuam nessa área sobre a importância dessas variáveis, sua avaliação na rotina assistencial e sua consideração na implementação de intervenções que abordem aspectos psicológicos, de modo a reduzir o sofrimento psíquico, melhorando a adesão e o autocuidado, bem como favorecendo a adaptação à enfermidade em pacientes que vivem com HIV.

\section{REFERÊNCIAS}

Araújo, L. F., Teva, I., Quero, J. H., Reyes, A. O., \& Bermúdez, M. (2017). Analysis of resilience and sexual behavior in persons with HIV infection. Psicologia: Reflexão e Crítica, 30, 1-9. https://doi.org/10.1186/s41155-017-0076-6

Brasil. (2008). Manual de adesão ao tratamento para pessoas vivendo com HIV e aids. Ministério da Saúde.

Brasil. (2018a). Protocolo clínico e diretrizes terapêuticas para manejo da infecção pelo HIV em adultos. Ministério da Saúde, Secretaria de Vigilância em Saúde.

Brasil. (2018b). Boletim Epidemiológico HIV Aids, 59(53). Ministério da Saúde, Secretaria de Vigilância em Saúde.

Broadbent, E., Petrie, K. J., Main, J., \& Weinman, J. (2006). The Brief Illness Perception Questionnaire. Journal of Psychosomatic Research, 60, 631-637. https://doi. org/10.1016/j.jpsychores.2005.10.020

Cal, S. F., de Sá, L. R., Glustak, M. E., \& Santiago, M. B. (2015). Resilience in chronic diseases: A systematic review. Cogent Psychology, 2, 1-9 https://doi.org/10.1080/23311908.2015. 1024928

Castro, E. K. de, Romeiro, F. B., de Lima, N. B., Lawrenz, P., \& Hass, S. (2015). Percepção da doença, indicadores de ansiedade e depressão em mulheres com câncer. Psicologia Saúde \& Doenças, 16(3), 359-372. https://doi. org/10.15309/15psd160307

Chen, S. L., Tsai, J. C., \& Lee, W. L. (2009). The impact of illness perception on adherence to therapeutic regimens of patients with hypertension in Taiwan. Journal of Clinical Nursing, 18(15), 2234-2244. https://doi.org/10.1016/j. ijnurstu.2010.07.005

Connor, K. M., \& Davidson, J. R. T. (2003). Development of a new resilience scale: The Connor Davidson Resilience Scale
(CD-RISC). Depression and Anxiety, 18, 76-82. https://doi. org/10.1002/da.10113

Costa, J. de M., Torres, T. S., Coelho, L. E., \& Luz, P. M. (2018). Adherence to antiretroviral therapy for HIV/AIDS in Latin America and the Caribbean: Systematic review and metaanalysis. Journal of the International AIDS Society, 1, e25066. https://doi.org/10.1002/jia2.25066

Foresto, J. S., Melo, E. S., Costa, C. R. B., Antonini, M., Gir, E., \& Reis, R. K. (2017). Adesão à terapêutica antirretroviral de pessoas vivendo com HIV/aids em um município do interior paulista. Revista Gaúcha de Enfermagem, 38(1), e63158. https://doi.org/10.1590/1983-1447.2017.01.63158

Garbin, C. A. S., Gatto, R. C. J., \& Garbin, A. J. I. (2017). Adesão à terapia antirretroviral em pacientes HIV soropositivos no Brasil: Uma revisão da literatura. Archives of Health Investigation, 6(2), 65-70. https://doi.org/10.21270/archi. v6i2.1787

Hull, M., Lange, J., \& Montaner, J. S. (2014). Treatment as prevention - Where next? Current HIV/AIDS Reports, 11(4), 496-504. https://doi.org/10.1007/s11904-014-0237-5

Leventhal, H., Brissette, I., \& Leventhal, E. A. (2003). The commonsense model of self-regulation of health and illness. In L. Cameron \& H. Leventhal (Eds.), The self regulation of health and illness behavior (pp. 42-65). Routledge.

Nogueira, G. S., \& Seidl, E. M. F. (2016a). Análise fatorial exploratória do Questionário de Percepção de Doenças Versão Breve (Brief IPQ). Psicologia: Teoria e Pesquisa, 32(1), 161168. https://doi.org/10.1590/0102-37722016011871161168

Nogueira, G. S., \& Seidl, E. M. F. (2016b). Associação entre percepção de doença e ansiedade, depressão e autoeficácia em pessoas vivendo com HIV/aids. Temas em Psicologia, 24(2), 595-608. https://doi.org/10.9788/TP2016.2-12 
Norcini, P. A., \& Steca, P. (2015). Illness perceptions and coping strategies among individuals diagnosed with HIV. Journal of Behavioral Medicine, 38(4), 620-631. https://doi.org/10.1007/ s10865-015-9639-0

Nosyk, B., Montaner, J. S. G., Colley, G., Lima, V. D., Chan, K., \& Heath, K. (2014). The cascade of HIV care in British Columbia, Canada, 1996-2011: A population-based retrospective cohort study. Lancet Infectious Disease, 14(1), 40-49. https://doi. org/10.1016/S1473-3099(13)70254-8

Petrie, K. J., \& Weinman, J. (2006). Why illness perceptions matter? Clinic Medical, 6, 536-539. https://doi.org/10.7861/ clinmedicine.6-6-536

Remor, E. (2002). Valoración de la adhesión al tratamiento antirretroviral en pacientes VIH+. Psicothema, 14(2), 262-267. http://www.psicothema.com/psicothema.asp?id=718

Remor, E. (2013a). Release of an online self-reporting tool for assessing adherence to antiretroviral therapy (CEAT-VIH). Journal of Antivirals and Antiretrovirals, 5, 178-179. https:// doi.org/10.4172/jaa.1000085

Remor, E. (2013b). Systematic review of the psychometric properties of the Questionnaire to Evaluate the Adherence to HIV Therapy (CEAT-VIH). The Patient, 6, 61-73. https://doi. org/10.4172/jaa.1000085

Remor, E., Milner-Moskovics, J., \& Preussler, G. (2007). Estudo psicométrico para a adaptação brasileira do "Cuestionario para la Evaluación de la Adhesión al Tratamiento Antirretroviral
(CEAT-VIH)". Revista de Saúde Pública, 41(5), 685-694. https://doi.org/10.1590/S0034-89102006005000043

Rooke, M. I. (2015). Aspectos conceituais e metodológicos da resiliência psicológica: uma análise da produção científica brasileira. Revista Estudos e Pesquisas em Psicologia, 15(2), 2-15.http://pepsic.bvsalud.org/scielo.php?script=sci_arttext\& pid $=\mathrm{S} 1808-42812015000200013$

Silva, R. A. R., Nelson, A. R. C., Duarte, F. H. S., Prado, N. C. C., Holanda, J. R. R., \& Costa, D. A. R. S. (2017). Avaliação da adesão à terapia antirretroviral em pacientes com Aids. Revista de Pesquisa: Cuidado é Fundamental Online, 9(1), 15-20. https://doi.org/10.9789/2175-5361.2017. v9i1.15-20

Silva, B. de B., de Brito, A., Monteiro, E. P., Mondelo, G. P., \& Remor, E. (2019). Evidence of validity for the online version of the Assessment of Adherence to Antiretroviral Therapy Questionnaire. SAGE Open, July-September, 1-12. https://doi. org/10.1177/2158244019877201

Solano, J. P., Bracher, E., Faisal-Cury, A., Ashmawi, H., Carmona, M. J., Lotufo-Neto, F., \& Vieira, J. (2010). Factor structure and psychometric properties of the Connor-Davidson resilience scale among Brazilian adult patients. São Paulo Medical Journal, 134(5), 400-406. https://doi.org/10.1590/15163180.2015 .02290512

Stewart, D. E., \& Yuen, T. (2011). A systematic review of resilience in the physically ill. Psychosomatics, 52(3), 199-209. https:// doi.org/10.1016/j.psym.2011.01.036 